\title{
ACCREDITATION AND HEALTH CARE QUALITY ASSURANCE IN PAKISTAN: A DESK REVIEW
}

\author{
Fauziah Rabbani ${ }^{1}$ and Imran Naeem Abbasi ${ }^{2}$
}

1,2 Department of Community Health Sciences Health Systems \& Policy Research Group Aga Khan University Karachi, Pakistan

Correspondence: Imran Naeem Abbasi. Email: Imran.naeem@aku.edu, Cell: 021-34865056

\begin{abstract}
Background: Pakistan has a well-established healthcare system with $70 \%$ healthcare needs catered by private health sector. The latter's unregulated and unchecked expansion has resulted in quackery and compromised quality of care. This situation analysis provides a snapshot of health system's quality assurance and accreditation processes.

Methods: Two validated questionnaires from World health Organization gauged the current state of health care accreditation and quality of care initiatives in Pakistan. Information was obtained from peer reviewed articles, grey literature, policy documents on government websites and newspapers.

Results: Pakistan has a number of regulatory bodies responsible for ensuring quality in healthcare through accreditation and defined standards. National Institute of Health issues updated clinical quality guidelines pertaining to disease epidemics. A national quality policy was also formulated in 2004. However, implementing and ensuring accreditation has been challenging. Though statutory bodies are in place for registering different cadres of healthcare professionals, policies and mechanisms regarding licensure of healthcare establishments are missing. Emergence of national health vision 2012-2020, provincial health sector strategies and healthcare commission acts have focused on regulation of private health sector and accreditation of healthcare establishments. Despite presence of regulatory bodies, there are implementation gaps.

Conclusion: This paper highlights some important gaps regarding accreditation and quality in healthcare. Quality assurance should be incorporated into national health policies, programs and strategies. National health policy should include explicit laws concerning quality Indicators and standards for quality in health care. Need to regulate private health sector and ensuring quality in overall healthcare is more than ever.
\end{abstract}

Keywords: Regulation, accreditation, healthcare quality, private sector, licensure, policy, Pakistan

\section{Introduction}

Pakistan's health care system is a three-tiered health care delivery system: primary, secondary and tertiary care. Health service delivery starts at grass root level where health houses provide community health care services through lady health workers and are connected to basic health units (BHUs) with an upward referral pathway to rural health centres (RHCs), tehsil hospitals and district hospitals. There are also well-equipped tertiary level teaching hospitals $(1,2)$. Overall there are approximately 1474 hospitals, 5336 BHUs and 560 RHCs. Despite more number of BHUs and RHCs compared to hospitals, majority of burden of service delivery is borne by secondary and tertiary care hospitals (3).

However, this extensive health care infrastructure has not been translated into optimal health care delivery due to a number of issues related to the health system. This includes the poor motivation of the health workforce due to lack of credible career structure and work environments, mal-distribution of resources between urban and rural areas, and the lack of a national human resources for health policy (1).

World health organization (WHO) has devised a strategy to promote information systems for monitoring and calls for active surveillance by national governments for implementation of international norms, standards and regulations. In Pakistan there is a deficient system of quality assurance. There is no ongoing certification of health professionals nor accreditation of health institutions.

Pakistan spends only $0.5 \%$ of its gross domestic product (GDP) on health, which is very low(3). This leads to an inability of the public sector to provide the required medicines and laboratory equipment for effective health care delivery resulting in out-of-pocket expenditure of around $80 \%$. It is therefore not surprising that private sector caters to the majority of healthcare needs of the population $(1,2)$.

Private sector comprises of a range of services such as hospitals, clinics run by individual practitioners, maternity homes, nursing homes, physio-therapy 
centers, diagnostic facilities (laboratories, radiology centers) and pharmacies in addition to practitioners of traditional and alternative medicine (2).

While the quality of service delivery is less than optimal in public sector there is variation in the quality of services provided through private sector. A large number of unregulated hospitals and clinics are operating privately and the number of healthcare professionals working in these healthcare facilities considerably exceeds that of public sector $(1,2)$.

Lack of regulation has led to uncontrolled expansion of private sector where anyone can open a clinic, hospital or diagnostic facility with the only requirement of having qualified practitioners. While private sector has helped cope the unmet need and fill gaps in health service delivery in the country, lack of regulatory mechanisms and absence of check and balance has also led to poor quality of services and given way to all forms of malpractice (quackery). Because of this several of the allopathic, traditional/alternative medicine clinics and other healthcare and diagnostic facilities are being operated by un-qualified staff $(2,3)$.

This descriptive paper constitutes a snapshot of healthcare quality and accreditation in healthcare in Pakistan. It reviews the current status of legislation i.e. policies on licensure and accreditation of healthcare professionals and healthcare facilities; and the presence of regulatory bodies to ensure the implementation of such policies. The aim is to make a significant contribution to the documentation of structures and processes that may help to inform local improvement of health services at the national level.

\section{Methodology}

Two WHO validated questionnaires were used to gauge the current status of healthcare accreditation and quality of healthcare initiatives in Pakistan:

Tool 1: Quality of care questionnaire

This tool (4) obtained information on policies relating to quality of healthcare, infrastructure assessment and improvement initiatives (table 1).

Tool 2: Healthcare accreditation questionnaire

The questionnaire consisted of questions relating to policy and practice of licensure and accreditation of healthcare professionals and healthcare establishments (hospitals, clinics, laboratories, pharmacies and blood banks) (table 1).

To complete the questionnaires, information was obtained from peer reviewed research articles, grey literature and newspapers. The websites of the national health ministry, national programs, national institutions and the WHO were explored to extract relevant reports and policy documents.

\section{Results}

The results synthesize evidence obtained from both tools and present information on regulatory bodies ensuring quality of health care, legal and regulatory frameworks governing them, compliance of various national programs with quality standards and available disease specific quality care guidelines and initiatives (figure 1). Moreover it landscapes the licensure and accreditation status of various health care professionals and health facilities (figure 2).

A) Policies and regulatory bodies to ensure quality in healthcare (table 2)

Ministry of Science and Technology (MoST)

It is the national focal point and enabling arm of Government of Pakistan for planning, coordinating and directing efforts; to initiate and launch scientific and technological programs and projects (5). Pakistan Standards and Quality Control Authority (PSQCA) and Pakistan National Accreditation Council (PNAC) both come under administrative control of MoST.

Pakistan Standards and Quality Control Authority (PSQCA)

Working under the ministry of science and technology and governed by the PSQCA Act 1996, PSQCA was established in 2000. It is the national standardization body responsible for creating and assessing conformity to the quality standards. PSQCA has defined quality standards for primary, secondary and tertiary level healthcare facilities which include pre-requisites for opening a healthcare facility and resources required to ensure its smooth operation (6). Most of the work in terms of healthcare, however, has remained on paper and there is lack of compliance by healthcare facilities with the defined standards.

Pakistan National Accreditation Council (PNAC)

PNAC was established in 1998 and provides accreditation to various entities, according to international standards, including clinical laboratories. However, this accreditation is voluntary. There is no mandatory requirement to get accredited from PSQCA before establishing clinical laboratories (7).

National Quality Policy and Plan (2004)

Realizing that a comprehensive quality policy was needed to address the emerging global requirements of trade, environment, health and safety of the consumers, PNAC initiated work on the formulation of a National Quality Policy \& Plan which was completed in 2004 (8). Unfortunately this policy remained on paper only as no part of it translated into action.

Drug Regulatory Authority of Pakistan (DRAP)

DRAP is responsible for licensing of drug manufacturing units and registration of drugs, biological and health products, and medical devices. Responsibilities of DRAP also include ascertainment of standards compliance by making periodic inspections of the drug manufacturing units and taking necessary legal action as required(9).

\section{The National Blood Transfusion Service (NBTS)}

The National Blood Transfusion Service (NBTS) established a National Strategic Framework 2008-2012 for blood transfusion services in Pakistan, which was officially approved in March 2009. Based on that framework, the NBTS has drafted and subsequently promulgated the federal blood transfusion law to guide 
legislative reforms at provincial level. It has also established a national steering committee and completed an inventory of existing teaching and training facilities. In one district, it has conducted a survey of knowledge, attitudes and practices related to blood donation, while at the federal level it has carried out an instructors' training course for quality management for trainers (10).

\section{National infection control guidelines}

Given lack of national policy on infection control, in 2006 guidelines were developed to provide healthcare practitioners with national standards to control spread of infection (11). Some of the national programs have defined the disease specific clinical practice related quality guidelines. These programs include: a) National Maternal, Neonatal and Child Health $(\mathrm{MNCH})$ Program; b) National AIDS Control Program; c) National Tuberculosis Control Program; d) Malaria Control Program; e) Dengue Control Program.

Other guidelines developed by National Institute of Health Pakistan are as follows:

a) guidelines for the prevention, control and management of Middle East Respiratory SyndromeCoronavirus (MERS-CoV); b) allergy booklet in Urdu for patients and general public; c) guidelines on avian influenza bird flu 2008; d) guidelines for Crimean Congo Hemorrhagic Fever (CCHF); e) pandemic influenza $\mathrm{H} 1 \mathrm{~N} 1$; f) influenza H1N1; g) guidelines for control of vectors of public health importance after monsoon rains in Pakistan.

Quality Improvement Initiatives and Activities

a) In Pakistan, "Save Lives: Clean Your Hands" campaign was launched in 2009 as a follow-up to WHO's "first global patient safety challenge: clean care is safer care" to improve hand hygiene in health care and prevent life threatening healthcare-associated infections (HAl).

b) WHO surgical safety checklist and manual though committed but was not implemented except for a few feasibility studies conducted in different hospitals.

c) WHO Patient Safety Friendly Hospital Initiative (PSFHI) was piloted at tertiary hospital i.e. Pakistan Institute of Medical Sciences (PIMS) in 2010. A patient safety centre was established for implementation of safe health practices based on standardized protocols

d) Contracting out of BHUs to third parties in order to improve the quality of healthcare delivery in primary healthcare

e) Recent introduction of Continuing Medical Education (CME) programs by College of Physicians and Surgeons Pakistan (CPSP) is an initiative to improve quality of education in medical field

B) Policies and practice of licensure and accreditation of healthcare professionals and healthcare establishments (table 3 )

Pakistan Medical and Dental Council (PMDC)

PMDC is a statutory regulatory authority established under Pakistan medical \& dental council ordinance 1962. PMDC is responsible for registration of medical and dental practitioners and issues a certificate which enables them to practice in public or private healthcare institutions. It is also responsible for accrediting medical and dental schools and formulating guidelines for undergraduate and postgraduate training and qualification (12)

Pakistan Nursing Council (PNC)

PNC is an autonomous, regulatory body constituted under the Pakistan nursing council act (1952 and 1973).

It issues license of practice to nurses, midwives, lady health visitors (LHVs) and nursing auxiliaries. PNC is responsible for inspecting educational institutes (nursing) for purposes of accreditation and maintaining education standards (13).

Pharmacy Council Pakistan (PCP)

PCP is the regulatory body established under the pharmacy act 1967 to regulate pharmacists and pharmacy premises in Pakistan. It is responsible for registration of pharmacists and promotion of pharmacy education in the country (14).

National council for homoeopathy and national council for Tibb

Both the national council for homeopathy and the national council for Tibb are the regulatory bodies constituted under unani, ayurvedic and homoeopathic practitioners act 1965 . These are responsible for registration of practitioners of unani, ayurvedic and homoeopathic practitioners. Both of the regulatory bodies have the responsibility to accredit educational institutes and inspect them to ensure compliance with council's defined standards of education $(15,16)$.

\section{Discussion}

Positive Initiatives to improve quality of care in Pakistan and the region

There have been a number of initiatives related to quality in healthcare including formulation of national quality policy and plan - 2004 by PNAC (8). In addition PSQCA has played its role by defining national quality standards for primary, secondary and tertiary healthcare facilities (6).

Moreover the National Institute of Health has been playing active role by providing updated guidelines on prevention and control of emerging infectious diseases and their management. Similarly, certain national programs such as malaria, AIDS, tuberculosis control and $\mathrm{MNCH}$ programs provide clear guidelines in order to maintain quality of health and healthcare (17). Initiative of contracting out the primary healthcare facilities to third parties has been a welcome addition to quality improvement in healthcare. The national blood transfusion services initiative has been a long awaited development given the rising trend of hepatitis $B$ and $C$ cases in the country (10). Moreover, role of DRAP in 
defining standards related to manufacturing and sale of drugs has been pivotal.

Following devolution in 2010, health sector strategies were developed by the provinces that defined a minimum package of health services to be made available at the level of primary healthcare facilities. The Sindh health sector strategy, for example, lists regulation of private health sector and a mandatory licensure for healthcare facilities to ensure quality of healthcare as one of its key objectives (18).

Three (Sindh, Punjab and Khyber PukhtunKhwa) of the four provinces have developed the so called healthcare commission acts defining the policies and legislation for licensure and accreditation of healthcare institutions that also cover private health sector (19-21).

As mentioned, these acts have clearly defined rules and procedures to obtain a mandatory license prior to establishing any healthcare institutions. Moreover, compliance with a set of standards is required prior to issuing of such license failing which could lead to cancellation of such license. However, some clarity on the set of standards and the entity responsible to develop these is still required. Similarly, provincial blood transfusion programs, under the blood transfusion act 1997 have been developed to ensure availability of safe blood to recipients and regulation of blood banks for the same purpose (10).

Development of healthcare acts by the provinces is an important and long-awaited step in terms of regulation of private sector. This can not only ensure inclusion of private sector in main health service delivery stream of the country, but also improve the quality of services. True value of these measures, however, can only be realized if and when these policies translate into practice.

More recently announced National health vision 2012 2020 also talks about the need to introduce mechanism for not only regulating the private health sector but also increasing synergies between the public and private sectors for optimal health service delivery. The national vision has also emphasized the need to strengthen the licensing mechanisms for healthcare professionals (22). In Eastern Mediterranean (EMR) region, some of the countries seem to be doing well in terms of private sector regulation and health care accreditation while others are making progress but are still in an early phase. It is worth mentioning the success story of Iran in terms of private sector regulation and healthcare accreditation. The private sector is regulated through both the Iranian medical association and the ministry of health and medical education. Iran has also developed national accreditation system for hospitals whereas some independent accreditation organizations are also operating in the country (23).

Kuwait is another country in the EMR region with strong regulatory mechanisms in place for the private health sector. About $80 \%$ of all healthcare services are provided by public health sector. Private sector caters only to the $20 \%$ of health services under the regulation of ministry of health. Similarly national accreditation program provides accreditation to hospitals and clinics in order to ensure quality of health (24). Similarly, Yemen and Egypt have laws for mandatory licensing of private healthcare facilities (25).

Afghanistan, for a long time has been impacted by war and insurgency which has affected its healthcare services. Recent development by the ministry of health have led to some policy initiatives addressing the long awaited issue of private health sector regulation (26).

Gaps in demand and supply of quality assurance in Pakistan \& the region

When it comes to quality in healthcare at national level, despite having a common goal of improving healthcare quality all efforts seem to be happening in silos. What has been missing is lack of integration of healthcare quality in the national health policies resulting in a huge gap in terms of availability of national guidelines on healthcare quality. PNAC is mandated with facility accreditation (clinical laboratories) however this is not mandatory (7). This again leads to lack of standardization with variability in quality of services across clinical laboratories.

In terms of accreditation and licensure, the focus primarily has been on individuals rather than healthcare institutions. Licensing and regulation of healthcare establishments has been a neglected area in the national health policies.

Despite existence of regulatory bodies for licensure of health care professionals, there are implementation gaps. Unchecked population growth that is unmatched with the concurrent expansion of public healthcare system has created a demand and supply gap. This in turn has paved way for private sector where in addition to few accredited hospitals, many unregulated hospitals and clinics, unqualified practitioners, quacks (homeopaths and hakeems) have been active in healthcare service delivery $(2,3,27)$. The regulatory bodies have been more active in accrediting educational institutions with little to no attention to control of malpractice in healthcare service delivery.

In India, like Pakistan, private sector is a major stakeholder in healthcare service delivery due to poor quality of healthcare and insufficient number of facilities in public sector. However, the expansion in private health sector is not accompanied by a concurrent regulation to ensure licensing and registration of private health facilities. Nonetheless, there are recent developments (Clinical establishment act, 2010) awaiting effective implementation (28). Similarly in Bangladesh, though the policies regarding licensure and registration of private healthcare establishments are in place, the currently implemented licensing and accreditation system is considered outdated and ineffective $(29,30)$. Rules of engagement between public \& private sector in Pakistan

Despite the fact that national health policy 2001 emphasized drafting laws for regulation and 
accreditation, the proactive private sector in Pakistan still remains largely unregulated. There is lack of regulatory (licensure) bodies for practitioners of physical medicine, laboratory technicians and radiographers and for healthcare establishments operated by these cadres of healthcare professionals. Absence of accreditation of healthcare institutions is an important cause of prevailing dismal quality of services despite the presence of licensed healthcare professionals.

\section{Conclusion}

Implementing and ensuring accreditation in healthcare in Pakistan has been challenging. Though statutory bodies are in place for registering different cadres of healthcare professionals, policies and mechanisms regarding licensure of healthcare establishments have been missing since Pakistan's establishment in 1947. Quality assurance should be incorporated into national health policies, programs and strategies with a clearly articulated vision. National health policy should include explicit laws, and regulations concerning quality Indicators and standards for quality assurance in health care. Health facilities and health providers should be professionally incentivized for participation in quality improvement initiatives. Government requirements for funding contracts with practitioners, hospitals, and health care organizations should emphasize quality assurance and cyclical accreditation.?

\section{References}

1. Shaikh BT, Hatcher J. Health seeking behaviour and health service utilization in Pakistan: challenging the policy makers. Journal of public health. 2005;27(1):49-54.

2. Shaikh BT. PRIVATE SECTOR IN HEALTH CARE DELIVERY: A REALITY AND A CHALLENGE IN PAKISTAN. Journal of Ayub Medical College Abbottabad. 2015;27(2):496-8.

3. World Health Organization. Health System Profile Pakistan. 2007 [updated 2007; cited 201617 october]; Available from: http://apps.who.int/medicinedocs/documents/s 17305e/s17305e.pdf.

4. World Health Organization. Health at a Glance: Asia/Pacific 2014 Measuring Progress towards Universal Health Coverage: Measuring Progress towards Universal Health Coverage. OECD Publishing; 2014.

5. Pakistan. MoSaTGo. Ministry of Science and Technology Government of Pakistan.; 2016 [updated 2016; cited 2016]; Available from: http://www.most.gov.pk/.

6. Pakistan Standards and Quality Control Authority Standards Development Centre (SDC). 2016 [updated 2016; cited 201617 October]; Available from: http://www.psqca .com.pk/sdc/Hospital\%20\&\%20Healthcare\%20 Facilities.htm.

7. Pakistan National Accreditation Council. Pakistan National Accreditation Council 2016 [updated 2016; cited 201617 October]; Available from: $\mathrm{http}: / /$ pnac.org.pk/.

8. Pakistan National Accreditation Council, Ministry of Science and Technology, Pakistan. Go. NATIONAL QUALITY POLICY AND PLAN. 2004 [updated 2004; cited]; Available from: http://most.comsatshosting.com/ $\% 5$ CPolicies $\%$ 5CNQPAndP-PNAC.pdf.

9. Drug Regulatory Authority of Pakistan. Drug Regulatory Authority of Pakistan. 2016 [updated 2016; cited 201617 October]; Available from: http://www.dra.gov.pk/.

10. Safe Blood Transfusion program: Government of Pakistan. Safe Blood Transfusion program: Government of Pakistan. 2016 [updated 2016; cited 201617 October]; Available from: http://sbtp.gov.pk/.

11. Ministry of Health Pakistan. National Guidelines for Infection Control.; 2006 [updated 2006; cited 2016]; Available from: http://www.nacp.gov.pk/ repository/howwework/Technical\%20Guideline s/Treatment $\% 20 \& \% 20$ Care/Guideline $\% 20 f o r \%$ 20Infection\%20Control(Part-1).pdf.

12. Pakistan Medical \& Dental Council. Pakistan Medical \& Dental Council. 2016 [updated 2016; cited 201617 October]; Available from: http://www.pmdc.org.pk/.

13. Pakistan Nursing Council. Pakistan Nursing Council 2016 [updated 2016; cited 201617 October]; Available from: www.pnc.org.pk/.

14. Pharmacy Council Pakistan. Pharmacy Council Pakistan. 2016 [updated 2016; cited 201617 October]; Available from: http://www.pharmacy council.org.pk/index.php.

15. National Council for Homeopathy. National Council for Homeopathy. 2016 [updated 2016; cited 201617 October]; Available from: www.nchpakistan.gov.pk.

16. National Council for Tibb. National Council for Tibb. 2016 [updated 2016; cited 201617 October]; Available from: www.nct.gov.pk/.

17. National Institute of Health Islamic Republic of Pakistan. Guidelines. 2014 [updated 2014; cited 2016]; Available from: http://www.nih.org .pk/Guid_Lin.asp.

18. Government of Sindh. Sindh Health Sector Strategy 2012 - 2020. 2012 [updated 2012; cited 2016]; Available from: http://www.trfpakistan .org/LinkClick. aspx?fileticket=1EyZSVflMkg\%3 D\&tabid $=2618$.

19. The Khyber PukhtunKhwa Health Care Commission. The Khyber Pakhtunkhwa Health Care Commission Act, 2015. 2015 [updated 2015; cited 201617 October]; Available from: http://www.pakp.gov.pk/2013/acts/the-khyberpakhtunkhwa-health-care-commissionact2015/.

20. Punjab Healthcare Commission. Punjab 
Healthcare Commission Act 2010. 2010 [updated 2010; cited 201617 October]; Available from: http://www.phc.org.pk/ downloads/PHC_Final_Act.pdf.

21. Sindh Healthcare Commission. Sindh Healthcare Commission Act 2014. 2014 [updated 2014; cited 201617 October]; Available from: http://www.pas.gov.pk/ uploads/acts/Sindh\%20Act\%20No.VII\%20of\% 202014.pdf.

22. Ministry of National Health Services Regulation and Coordination Government of Pakistan. National Health Vision Pakistan 2016-2025. 2016 [updated 2016; cited 2016]; Available from: http://202.83.164.28/new/userfiles/file/2016\%2 Onhsrc/National\%20Health\%20Vision\%202016 -25_30-08-2016.pdf.

23. Bahadori M, Ravangard R, Alimohammadzadeh $\mathrm{K}$. The accreditation of hospitals in iran. Iranian journal of public health. 2015;44(2):295-6.

24. World Health Organization. Health System Profile Kuwait. 2006 [updated 2006; cited 20169 December]; Available from: http://apps.who.int/ medicinedocs/documents/s17297e/s17297e.pd f.

25. Zaidi S, Riaz A, Thaver A, Mukhi A, Khan LA. Role and contribution of private sector in moving towards universal health coverage in the eastern mediterranean region. 2012.

26. Cross HE, Sayedi O, Irani L, Archer LC, Sears K, Sharma S. Government stewardship of the forprofit private health sector in Afghanistan. Health Policy and Planning. 2016:czw130.

27. Nishtar S, editor. The Gateway Paper: Health Systems in Pakistan, a Way Forward; 2006. Pakistan's Health Policy Forum.

28. Phadke A. Regulation of Doctors and Private Hospitals in India. Economic \& Political Weekly. 2016;51(6):47.

29. Bangladesh Medical \& Dental Council (BM\&DC). Bangladesh Medical \& Dental Council (BM\&DC) - The Regulatory Authority in Bangladesh. 2016 [updated 2016; cited 201617 October]; Available from: http://bmdc.org .bd/news/notice/.

30. Roy A. The Need for Regulatory Reform to Improve Rural People's Access to Healthcare: Views of Administrators of the Public-private Mixed Health System of Bangladesh. Diversity \& Equality in Health and Care. 2016. 